\title{
Komposisi Jenis dan Kelimpahan Zooplankton di Perairan Teluk Buli, Halmahera Timur
}

\author{
Yuliana*, Fasmi Ahmad** \\ *Staf Pengajar Fakultas Perikanan dan Ilmu Kelautan Universitas Khairun, Ternate, \\ Email: yulianarecar@gmail.com \\ **Pusat Penelitian Oseanografi (P2O-LIPI), Jakarta
}

\begin{abstract}
ABSTRAK
Keberadaan ikan dan kesuburan perairan merupakan salah satu indikator adanya zooplankton, mengingat peranan zooplankton dalam ekosistem sebagai konsumer pertama yang memakan fitoplankton, kemudian zooplankton dimakan oleh anakanak ikan. Berdasarkan fungsi zooplankton dalam perairan tersebut, maka sangat penting untuk melakukan penelitian tentang kondisi zooplankton terutama terkait dengan komposisi jenis dan kelimpahan di perairan Teluk Buli Kabupaten Halmahera Timur. Tujuan dari penelitian ini adalah untuk mengetahui komposisi jenis dan kelimpahan zooplankton di perairan Teluk Buli Halmahera Timur. Penelitian dilaksanakan pada bulan Desember 2014 di perairan Teluk Buli Kabupaten Halmahera Timur Provinsi Maluku Utara pada 5 (lima) stasiun. Pengambilan sampel zooplankton menggunakan metode penyaringan dengan melakukan penarikan plankton secara horizontal selama 5 menit di bagian permukaan laut (kedalaman 0,5 meter). Hasil penelitian menunjukkan bahwa terdapat 33 jenis zooplankton dengan kelimpahan yang berkisar antara 4.567,84 - 19.321,61 ind/m3. Indeks-indeks biologi zooplankton berturut-turut dengan kisaran adalah indeks keanekaragaman $\left(H^{\prime}\right): 1,5286$ 1,9282, indeks keseragaman $(E)$ : 0,4945 - 0,6238, dan indeks dominansi $(D)$ : $0,1926-0,3389$.
\end{abstract}

Kata Kunci : kelimpahan, komposisi jenis, Teluk Buli, dan zooplankton

\section{PENDAHULUAN}

Perairan pesisir merupakan salah satu perairan yang memberikan manfaat yang besar terhadap ekosistem-ekosistem di sekitarnya serta terhadap organisme yang hidup dan berasosiasi di dalamnya. Pada perairan ini hidup berbagai jenis biota yang saling berinteraksi dan bersimbiosis antara satu dengan yang lainnya. Oraninesme-organisme tersebut antara lain adalah nekton, benthos, dan plankton.

Plankton yang terdiri atas fitoplankton dan zooplankton merupakan makanan alami bagi larva organisme di perairan laut. Sebagai produsen primer, fitoplankton memiliki kemampuan untuk memanfaatkan sinar matahari sebagai sumber energi dalam aktivitas kehidupannya. Sementara itu, zooplankton berkedudukan sebagai konsumen primer dengan memanfaatkan sumber energi yang dihasilkan oleh produser primer (Lagus et al., 2004; Andersen et al., 2006).

Produksi primer fitoplankton dalam suatu perairan dikontrol oleh kehadiran zooplankton pada perairan tersebut. Kehadiran dan kelimpahan zooplankton sangat erat kaitannya dengan perubahan lingkungan dan ketersediaan makanan. Organisme ini hanya dapat hidup dan berkembang dengan baik pada kondisi perairan yang sesuai seperti perairan laut, sungai, dan waduk. Apabila kondisi lingkungan sesuai dengan kebutuhan zooplankton, maka zooplankton akan tumbuh dan berkembang dengan baik. Begitu pula sebaliknya, jika kondisi lingkungan dan ketersediaan fitoplankton tidak sesuai dengan 
kebutuhan zooplankton, maka zooplankton 3 tidak dapat bertahan hidup dan akan mencari kondisi lingkungan yang sesuai (Thoha, 2004).

Kondisi lingkungan yang sesuai bagi zooplankton dapat ditemukan pada perairanperairan yang tidak mendapat tekanan ekologis dari daratan ataupun dari perairan itu sendiri. Kondisi perairan seperti itu sangat dipengaruhi oleh berbagai aktivitas yang dilakukan oleh masyarakat, baik kegiatan yang dilakukan di daratan maupun kegiatan pada perairan bersangkutan. Demikian halnya keberadaan zooplankton sangat dipengaruhi oleh berbagai kegiatan yang dilakukan oleh masyarakat yang bermukim di sekitar perairan Teluk Buli.

Perairan Teluk Buli Halmahera Timur merupakan salah satu perairan di Maluku Utara yang memiliki potensi yang besar, baik dari segi ekonomi maupun ekologis. Dari segi ekonomi perairan ini berpotensi sebagai lokasi budidaya laut (marine culture) dan lokasi penangkapan ikan bagi masyarakat nelayan di pesisir. Sementara itu, dari segi ekologi perairan ini menjadi pendukung bagi perairanperairan di sekitarnya dan penyedia berbagai sumberdaya yang terdapat di dalamnya. Agar organisme yang ada di perairan ini tetap lestari dalam menunjang kesinambungan ekosistemnya, maka perairan ini harus dijaga supaya tetap menunjang diversitas organisme di sekitar pantai dan menghasilkan nilai tambah dari segi estetika dan ketersediaan ikan.

Keberadaan ikan dan kesuburan perairan merupakan salah satu indikator adanya zooplankton, mengingat peranan zooplankton dalam ekosistem sebagai konsumer pertama yang memakan fitoplankton, kemudian zooplankton dimakan oleh anak-anak ikan. Berdasarkan fungsi zooplankton dalam perairan tersebut, maka sangat penting untuk melakukan penelitian tentang kondisi zooplankton terutama terkait dengan komposisi jenis dan kelimpahan di perairan Teluk Buli Kabupaten Halmahera Timur. Tujuan dari penelitian ini adalah untuk mengetahui komposisi jenis dan kelimpahan zooplankton di perairan Teluk Buli Halmahera Timur. Hasil penelitian ini diharapkan dapat memberikan petunjuk tentang kondisi perairan Teluk Buli berdasarkan keberadaan zooplankton.

\section{METODE PENELITIAN}

Penelitian ini dilaksanakan pada bulan Desember 2014 di perairan Teluk Buli Kabupaten Halmahera Timur Provinsi Maluku Utara pada 5 (lima) stasiun (Gambar 1).

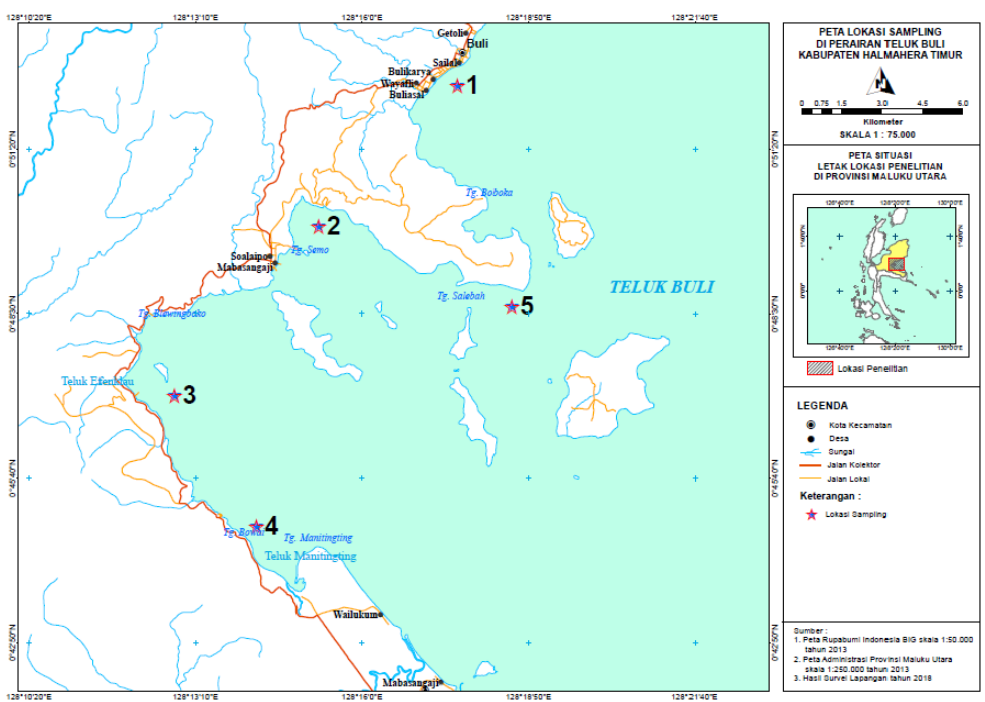

Gambar 1. Lokasi penelitian di perairan Teluk Buli Halmahera Timur Maluku Utara.

\subsection{Pencacahan Zooplankton}

Contoh air untuk spesimen zooplankton diambil dengan metode penyaringan dengan cara melakukan pengambilan secara horizontal pada bagian permukaan laut (kedalaman $0,5 \mathrm{~m}$ ) selama 5 menit. Hasil penyaringan dimasukkan ke dalam botol volume $110 \mathrm{ml}$ dan diawetkan dengan larutan formalin $4 \%$. 
Selanjutnya sampel tersebut diidentifikasi di Laboratorium Plankton Pusat Penelitian Oseanografi Jakarta, dengan berpedoman pada buku identifikasi dari Davis (1955), Yamaji (1979), dan Tomas (1997).

Kelimpahan jenis zooplankton dihitung berdasarkan persamaan sebagai berikut :

$$
K=n \times 1 / f \times 1 / v
$$

dengan :

$K=$ Nilai kelimpahan plankton (ind/liter)

$\mathbf{n}=$ Jumlah jenis plankton hasil pencacahan (ind)

$\mathbf{v}=$ Volume air tersaring (liter)

$\mathrm{f}=$ Volume sampel yang diamati

Indeks Shannon-Wiener digunakan untuk menghitung indeks keanekaragaman (diversity index) jenis, indeks keseragaman, dan indeks dominansi dihitung menurut Odum (1998) dengan rumus sebagai berikut :

1. Indeks keanekaragaman Shannon-Wiener :

$$
H^{\prime}=-\sum_{i=1}^{s}(\text { ni/N) } \ln (\text { ni/N) }
$$

2. Indeks keseragaman :

$$
\mathrm{E}=\mathbf{H}^{\prime} / \mathbf{H}_{\max }
$$

3. Indeks dominansi :

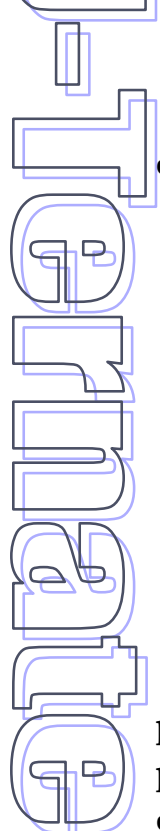

$$
D=\sum_{i=1}^{S}[\mathrm{ni} / \mathrm{N}]^{2}
$$

dengan :

$\mathbf{H}^{\prime}=$ Indeks keanekaragaman ShannonWiener

$\mathrm{E}=$ Indeks keseragaman

$\mathrm{D}=$ Indeks dominansi Simpson

ni $=$ Jumlah individu genus ke-i

$\mathbf{N}=$ Jumlah total individu seluruh genera

$H_{\max }=$ Indeks keanekaragaman maksimum (= ln $S$, dimana $S=$ Jumlah jenis)

Sebagai data penunjang dilakukan pengukuran beberapa parameter fisika-kimia perairan yang mempengaruhi pertumbuhan dan perkembangan zooplankton. Parameterparameter fisika-kimia tersebut adalah suhu, salinitas, kecepatan arus, dan pH yang dilakukan secara insitu (APHA, 2005).

\subsection{Analisis Data}

Data-data yang diperoleh dari penelitian ini ditampilkan dalam bentuk tabel dan grafik, dan khusus kelompok data penunjang akan dianalisis secara deskriptif. Untuk memudahkan perhitungan dalam analisis digunakan Excel Stat Pro 5.0

\section{HASIL DAN PEMBAHASAN}

\subsection{Komposisi Jenis Zooplankton}

Selama penelitian di perairan Teluk Buli ditemukan 33 jenis zooplankton. Jumlah genus yang didapatkan tersebut lebih banyak dibandingkan dengan penelitian Yuliana (2014) di Perairan Jailolo Halmahera Barat yang mendapatkan jumlah genus zooplankton hanya 7 genera, serta penelitian Ruga et al. (2014) di perairan Pulau Bunaken yang menemukan genus zooplankton sebanyak 28 genera. Jumlah genus yang ditemukan itu memiliki nilai yang tidak berbeda jauh antara setiap stasiun, dengan jumlah genus berkisar antara 18 - 23 genera. Genus terbanyak ditemukan pada stasiun 1 dan 3 dengan jumlah genus adalah 23 dan genus paling sedikit didapatkan pada stasiun 5 dengan jumlah yaitu 18 genera.

Jenis-jenis zooplankton yang ditemukan di perairan Teluk Buli tersebar dari stasiun 1 hingga stasiun 5. Jenis-jenis tersebut ada yang ditemukan pada semua lokasi pengamatan dan ada yang hanya terdapat pada beberapa stasiun saja. Jenis-jenis yang didapatkan pada semua lokasi pengamatan adalah Siphonophora, Chaetognatha, Evadne, Calanoida (Copepoda), Cyclopoida (Copepoda), Oikopleura, Pilidinium, Polychaeta, Ophiopluteus, Bivalvia, Creseis, dan Gastropoda. Hal ini mengindikasikan bahwa jenis-jenis tersebut memiliki sebaran yang luas dan dapat menyesuaikan diri dengan kondisi parameter fisika-kimia perairan di Teluk Buli.

Sementara itu, ada beberapa jenis yang hanya ditemukan pada satu stasiun. Jenis-jenis tersebut adalah Stenophores, Penelia, Ostracoda, Ephyra, Isopoda, Euphausiacea zoea, Thaliacea, Acetes zoea, Bipinnaria, telur ikan, dan larva ikan. Hal ini berarti bahwa jenisjenis tersebut hanya mampu menyeseauikan 
diri pada kondisi lingkungan di masing-masing stasiun ditemukan sehingga tidak memiliki distribusi yang luas di perairan Teluk Buli.

\subsection{Kelimpahan Zooplankton}

Berdasarkan pencacahan yang telah dilakukan, didapatkan bahwa kelimpahan zooplankton memiliki nilai yang bervariasi antara setiap stasiun, dengan kisaran antara $4.567,84-19.321,61 \mathrm{ind} / \mathrm{m}^{3}$ (Gambar 2). Nilai kelimpahan yang diperoleh tersebut lebih rendah bila dibandingkan dengan hasil penelitian Simanjuntak (2009) di perairan Belitung Timur yang mendapatkan kelimpahan zooplankton sebesar $28.270-70.680 \mathrm{ind} / \mathrm{m}^{3}$ dan penelitian Fitriya (2004) di Selat Makassar dengan kelimpahan zooplankton yang berkisar antara $276-1773 \mathrm{ind} / \mathrm{m}^{3}$. Tetapi lebih tinggi dari penelitian Tambaru et al. (2014) di perairan Pulau Badi Pangkep yang mendapatkan kelimpahan zooplankton adalah 55-225 ind/1 dan penelitian Thoha dan Rahman (2013) di Perairan Kepulauan Banggai yang memperoleh kelimpahan zooplankton yang berkisar antara $300-1722$ ind $/ \mathrm{m}^{3}$. Kelimpahan tertinggi ditemukan pada stasiun $5\left(19.321,61 \mathrm{ind} / \mathrm{m}^{3}\right)$ dan terendah $\left(4.567,84 \mathrm{ind} / \mathrm{m}^{3}\right)$ pada stasiun 3 (Gambar 2).

Kelimpahan tertinggi pada stasiun 5 disebabkan oleh parameter fisika-kimia yang mempengaruhi pertumbuhan dan perkembangan zooplankton pada stasiun ini berada pada kisaran yang sesuai. Parameter fisika-kimia tersebut berturut-turut adalah suhu : $2^{\circ} \mathrm{C}, \mathrm{pH}: 8,77$, salinitas : 35,5 , dan kecepatan arus : 53,6 cm/det. Selain itu, ketersediaan makanan pada stasiun ini cukup dan sesuai dengan kebutuhan zooplankton. Sebagaimana diketahui bahwa makanan merupakan faktor utama yang mempengaruhi pertumbuhan zooplankton. Makanan bagi zooplankton adalah fitoplankton, pada stasiun ini ditemukan jumlah kelimpahan fitoplankton yang cukup sehingga mengakibatkan zooplankton dapat tumbuh dengan baik karena makanan tersedia bagi zooplankton. Apabila ditelusuri lebih jauh didapatkan kelimpahan fitoplankton pada stasiun 5 adalah 148.148,15 ind $/ \mathrm{m}^{3}$.

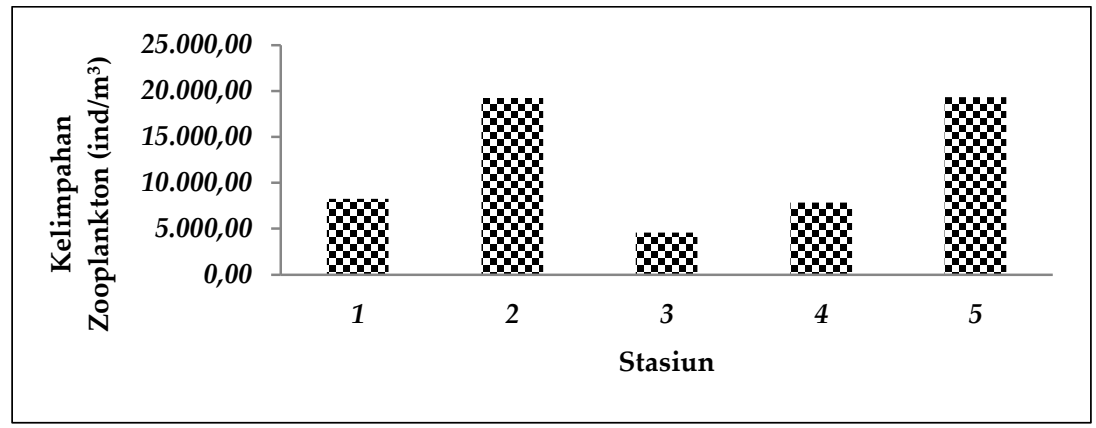

Gambar 3. Kelimpahan zooplankton selama penelitian di Perairan Teluk Buli Halmahera Timur.

Sementara itu, kelimpahan yang rendah pada stasiun 3 lebih disebabkan oleh makanan bagi zooplankton yaitu fitoplankton ketersediaannya tidak memadai pada stasiun ini. Dengan ketersediaan makanan yang terbatas atau tidak sesuai dengan kebutuhan zooplankton sehingga mengakibatkan organisme ini tidak dapat tumbuh dan berkembang secara maksimal. Selain itu, kelimpahan zooplankton yang rendah pada stasiun 3 disebabkan nilai $\mathrm{pH}$ yang rendah, pada stasiun ini nilai $\mathrm{pH}$ yang terukur adalah 3,65. Nilai $\mathrm{pH}$ yang rendah tersebut mengakibatkan zooplankton tidak dapat tumbuh dengan baik. Hal ini sesuai dengan yang dikemukakan oleh Effendi (2004) bahwa nilai $\mathrm{pH}<5,5$ mengakibatkan terjadinya penurunan kelimpahan total dan biomassa zooplankton.

Apabila kelimpahan zooplankton ditelaah lebih jauh per jenis, didapatkan bahwa genus Calanoida (Copepoda) memiliki kelimpahan tertinggi dibandingkan dengan jenis-jenis zooplankton yang lain. Kelimpahan Calanoida (Copepoda) yang didapatkan selama penelitian pada semua stasiun adalah $21.502,51$ 
ind $/ \mathrm{m} 3$. Sedangkan jenis yang paling sedikit ditemukan adalah Penelia, Ostracoda, Isopoda, dan larva ikan. Jenis-jenis tersebut memiliki kelimpahan masing-masing hanya sebesar 7,54 ind $/ \mathrm{m} 3$.

\subsection{Indeks-indeks Biologi}

Indeks-indeks biologi yang diamati adalah indeks keanekaragaman $\left(\mathrm{H}^{\prime}\right)$, indeks keseragaman (E), dan indeks dominansi (D). Indeks-indeks tersebut memperlihatkan kekayaan jenis dalam suatu komunitas serta keseimbangan jumlah individu tiap jenis. Hasil perhitungan indeks-indeks biologi zooplankton selengkapnya disajikan pada Tabel 1.

\section{Indeks}

keanekaragaman

zooplankton yang ditemukan di perairan Teluk Buli memiliki nilai yang rendah pada semua stasiun. Kisaran nilai indeks keanekaragaman yang ditemukan selama penelitian memiliki kisaran antara 1,5286 - 1,9282 (Tabel 1). Apabila nilai tersebut dikaitkan dengan kondisi perairan Teluk Buli, maka perairan ini termasuk dalam kategori dengan tingkat kesuburan sedang. Sebagaimana dikemukakan oleh Wilhm dan Dorris (1966) bahwa nilai keanekaragaman yang berada diantara 1 - 3 menunjukkan keanekaragaman sedang.

Tabel 1. Indeks-indeks biologi zooplankton yang ditemukan di perairan Teluk Buli Kabupaten Halmahera Timur

\begin{tabular}{crrr}
\hline \multirow{2}{*}{ Stasiun } & \multicolumn{3}{c}{ Indeks-indeks Biologi } \\
\cline { 2 - 4 } & $\mathrm{H}^{\prime}$ & $\mathrm{E}$ & $\mathrm{D}$ \\
\hline 1 & 1,8335 & 0,5848 & 0,2463 \\
2 & 1,9282 & 0,6238 & 0,1926 \\
3 & 1,7726 & 0,5653 & 0,2536 \\
4 & 1,5286 & 0,4945 & 0,3389 \\
5 & 1,7253 & 0,5969 & 0,2258
\end{tabular}

Keterangan: $H^{\prime}=$ Indeks Keanekaragaman, $E=$ Indeks Keseragaman, dan D = Indeks Dominansi

Nilai indeks keanekaragaman tertinggi ditemukan pada stasiun 2 dengan nilai $\mathbf{H}^{\prime}$ adalah 1,9282. Hal ini disebabkan antara lain oleh kualitas lingkungan yang lebih baik pada stasiun ini dibandingkan dengan stasiunstasiun yang lain. Sedangkan nilai indeks keanekaragaman terendah ditemukan pada stasiun 4 dengan nilai $H^{\prime}$ yaitu 1,5286 . Rendahnya indeks keanekaragaman pada stasiun 4 disebabkan oleh komunitas zooplankton yang ada pada stasiun ini sedang mengalami gangguan faktor lingkungan atau parameter-parameter lingkungan yang mempengaruhi pertumbuhan dan perkembangan zooplankton berada pada kondisi yang tidak sesuai.

Hampir semua stasiun pengamatan memiliki nilai indeks keseragaman ( E) di atas 0,5 , kecuali pada stasiun 4 . Kisaran nilai indeks keseragaman yang ditemukan pada perairan Teluk Buli adalah 0,4945 - 0,6238 (Tabel 1). Hal ini berarti bahwa kondisi komunitas zooplankton yang ada pada lokasi ini berdasarkan kriteria Daget (1976) berada pada kondisi tertekan hingga labil. Selama penelitian didapatkan bahwa komunitas zooplankton pada stasiun 1, 2, 3, dan 5 memiliki nilai yang berkisar antara 0,5653 - 0,6238 atau berada pada kisaran 0,50 $<\mathrm{E}<0,75$ berdasarkan kriteria Daget (1976), maka kondisi komunitas zooplankton pada lokasi-lokasi tersebut berada dalam kondisi labil. Sementara itu, pada stasiun 4 dengan nilai indeks keseragaman 0,4945 , komunitas zooplankton pada lokasi ini berada pada kondisi tertekan. Sebagaimana dikemukakan oleh Daget (1976) bahwa 0,00 < E $<0,50$ berarti komunitas berada pada kondisi tertekan. Nilai indeks keseragaman tertinggi terdapat pada stasiun 2 dengan nilai $\mathrm{E}=0,6238$ dan terendah pada stasiun 4 dengan nilai $\mathrm{E}$ adalah 0,4945. Selain itu, kondisi populasi zooplankton pada perairan Teluk Buli dapat dikatakan merata karena memiliki nilai yang mendekati 1.

Indeks dominansi zooplankton di perairan Teluk Buli selama penelitian memiliki nilai yang berkisar antara 0,1926 - 0,3389 (Tabel 1). Nilai yang ditemukan pada semua stasiun memiliki nilai yang mendekati 0 . Hal ini mengindikasikan bahwa di dalam struktur komunitas zooplankton yang sedang diamati tidak terdapat spesies yang secara ekstrim mendominasi spesies lainnya, parameterparameter fisika-kimia air berada pada kisaran yang sesuai sehingga tidak terjadi kompetisi, semua spesies memiliki peluang yang sama untuk dapat tumbuh dan berkembang dengan baik. Hal ini menunjukkan bahwa kondisi struktur komunitas dalam keadaan stabil, kondisi lingkungan cukup prima, dan tidak 
terjadi tekanan ekologis (stress) terhadap biota pada habitat bersangkutan.

\subsection{Kondisi Perairan}

Kondisi perairan Teluk Buli ditelaah berdasarkan beberapa parameter fisika-kimia perairan yang mempengaruhi pertumbuhan zooplankton. Parameter fisika dan kimia yang diukur meliputi suhu, salinitas, $\mathrm{pH}$, dan kecepatan arus.

Suhu perairan yang terukur selama penelitian memiliki nilai yang berkisar antara 28,68 - 29,49oC. Kisaran tersebut berada pada kisaran yang optimal bagi zooplankton. Hal ini sesuai dengan yang dikemukakan oleh Ruyitno (1980) bahwa secara umum suhu optimal bagi perkembangan plankton ialah $20^{\circ} \mathrm{C}-30^{\circ} \mathrm{C}$. Lebih lanjut dijelaskan oleh Manigasi (2013) bahwa suhu perairan mempengaruhi keberadaan zooplankton secara fisiologis dan ekologis. Secara fisiologis, perbedaan suhu perairan sangat berpengaruh terhadap umur dan ukuran zooplankton dewasa. Sementara itu, secara ekologis, perubahan suhu menyebabkan perbedaan komposisi dan kelimpahan zooplankton.

Salinitas yang terukur selama penelitian memiliki nilai yang berkisar antara $34,9-35,8$. Kisaran nilai itu sesuai untuk pertumbuhan plankton. Hal ini sejalan dengan yang dikemukakan oleh Sachlan (1982) bahwa plankton laut dapat hidup pada kisaran salinitas yang lebih besar dari 20.

Nilai $\mathrm{pH}$ yang didapatkan di perairan Teluk Buli adalah 3,65 - 8,77. Nilai pH yang terukur selama penelitian memiliki nilai yang tidak terlalu jauh berbeda pada stasiun 1, 2, 4, dan 5. Kecuali stasiun 3 yang memiliki nilai $\mathrm{pH}$ yang rendah yaitu 3,65. Koesoebiono (1981) menjelaskan bahwa $\mathrm{pH}$ air laut cenderung stabil dan konstan. Nilai kisaran $\mathrm{pH}$ pada stasiun 1, 2, 4, dan 5 sesuai untuk pertumbuhan plankton dan bukan merupakan faktor pembatas. Sebagaimana dijelaskan oleh Omori dan Ikeda (1984) bahwa pH air laut dianggap sebagai salah satu faktor utama yang membatasi laju pertumbuhan plankton laut jika nilai pH kurang dari 7,0 atau lebih dari 8,5.

Kecepatan arus di perairan Teluk Buli selama penelitian memiliki nilai yang berkisar antara 52,9 - 54,7 cm/det. Kecepatan arus sangat mempengaruhi dan berkaitan erat dengan kelimpahan dan distribusi zooplankton. Perairan yang memiliki kecepatan arus yang besar berdampak pada jumlah kelimpahan zooplankton. Pada perairan dengan kecepatan arus yang besar akan mengakibatkan nilai kelimpahan zooplankton menjadi kecil. Demikian pula sebaliknya, pada perairan yang memiliki kecepatan arus kecil, maka kelimpahan zooplankton akan menjadi besar. Menurut Mason (1981), kecepatan arus yang lebih kecil dari $0,5 \mathrm{~m} / \mathrm{s}$ tergolong arus yang sangat lambat. Kecepatan arus seperti itu memungkinkan aktivitas plankton berjalan dengan baik.

\section{PENUTUP}

\subsection{Simpulan}

Berdasarkan penelitian yang telah dilakukan, maka dapat disimpulkan bahwa :

1. Komposisi jenis zooplankton didominasi oleh genus Calanoida (Copepoda)

2. Kelimpahan zooplankton memiliki nilai yang berkisar antara $4.567,84-19.321,61$ ind $/ \mathrm{m} 3$.

3. Indeks-indeks biologi zooplankton seperti indeks keanekaragaman $\left(\mathrm{H}^{\prime}\right)$ termasuk dalam kategori sedang, indeks keseragaman (E) tergolong sedang, dan dari nilai indeks dominansi dapat dijelaskan bahwa tidak ada spesies yang mendominasi spesies yang lain.

\subsection{Saran}

Mengingat potensi yang dimiliki oleh perairan Teluk Buli, maka perlu dilakukan penelitian lanjutan secara berkala untuk mengetahui dan memantau kondisi perairan ini.

\section{DAFTAR PUSTAKA}

Andersen, J.H., L. Schluter, dan G. Aertebjerg. 2006. Coastal eutrophication : recent development in definitions and implication for monitoring strategis. Journal of Plankton Research, 28 (7) : 621-628. 
[APHA] American Public Health Association. 2005. Standard Methods for the Examination of Water and Wastewater, 21th Edition. Washington: APHA, AWWA (American Waters Works Association) and WPCF (Water Pollution Cobtrol Federation). hlm 3 - 42.

Daget, J. 1976. Les Modeles Mathematiques en Ecologie. Collection de Ecologic Masson, Paris.

Davis, G.C. 1955. The Marine and Freshwater Plankton. Michigan State University Press, USA. $526 \mathrm{p}$.

Effendi H. 2004. Telaah kualitas air bagi pengelolaan sumberdaya dan lingkungan perairan. Kanisius, Yogyakarta. 258 p.

Fitriya, N. 2004. Biota Planktonik : Fitoplankton. Dalam : Sopaheluwakan et al. (eds.) Biodiversitas Organisme Planktonik dalam Kaitannya dengan Kualitas Perairan dan Sirkulasi Massa Air di Selat Makassar. Laporan Akhir Program Pengembangan Kompetitif LIPI, Pusat Penelitian Oseanografi, Lembaga Ilmu Pengetahuan Indonesia, Jakarta. Hal. 24 - 25.

Lagus, A., J. Suomela, G. Wethoff, K. Heikkila, H. Helminen, dan J. Sipura. 2004. Species-specific Differences in Phytoplankton Responses to N and P Enrichment and The N:P ratio in The Archipelago Sea, Northern Baltic Sea. Journal of Plankton Research., 26 (7), 779-798.

Koesoebiono. 1981. Plankton dan Produktivitas Bahari. Faperi IPB Bogor: 173 hal

Manigasi, R., S.S. Tumembouw, dan Y. Mundeng. 2013. Analisis Kualitas Fisika Kimia Air di Areal Budidaya Ikan Danau Tondano Provinsi Sulawesi Utara. Budidaya Perairan. (2): 29 $-37$.

Mason, C.F. 1981. Biology of Freshwaater Pollution. London: Longman Group Limited. 250 p.

Odum, E.P. 1998. Dasar-dasar Ekologi : Terjemahan dari Fundamentals of Ecology. Alih Bahasa Samingan, T. Edisi Ketiga. Universitas Gadjah Mada Press, Yogyakarta. $697 \mathrm{p}$

Omori, M dan T. Ikeda. 1984. Method in Marine Zooplankton Ecology. Krieger Pub Co. 332p.

Ruga, L, M. Langoya, A. Papua, dan B. Kolondama. 2014. Identifikasi Zooplankton di Perairan Pulau Bunaken Manado. Jurnal MIPA Unsrat Online 3 (2) : 84 - 86.

Ruyitno. 1980. Lingkungan Laut dan Beberapa Faktor yang Mempengaruhi Lingkungan Laut. Pewarta Oseana Th VI/1

Sachlan, M. 1982. Planktonologi. Correspondence Course Centre. Direktorat Jenderal Perikanan, Departemen Pertanian, Jakarta. 141 p

Simanjuntak, M. 2009. Hubungan Faktor Lingkungan Kimia, Fisika terhadap Distribusi Plankton Perairan Belitung Timur, Bangka Belitung. Jurnal Perikanan (J. Fish. Sci.) XI (1): 31- 45

Tambaru, R., A.H. Muhiddin, dan H. S. Malida. 2014. Analisis Perubahan Kepadatan Zooplankton berdasarkan Kelimpahan Fitoplankton pada Berbagai Waktu dan Kedalaman di Perairan Pulau Badi Kabupaten Pangkep. Torani (Jurnal Ilmu Kelautan dan Perikanan). Vol.24 (3) : 40-48.

Thoha, H dan A. Rachman. 2013. Kelimpahan dan Distribusi Spasial Komunitas Plankton di Perairan Kepulauan Banggai. Jurnal Ilmu dan Teknologi Kelautan Tropis, Vol. 5 (1) : 145 $-161$.

Thoha, H. 2004. Biota Planktonik : Fitoplankton. Dalam : Sopaheluwakan et al. (eds.) Biodiversitas Organisme Planktonik dalam Kaitannya dengan Kualitas Perairan dan Sirkulasi Massa Air di Selat Makassar. Laporan Akhir Program Pengembangan Kompetitif LIPI, Pusat Penelitian Oseanografi, Lembaga Ilmu Pengetahuan Indonesia. Jakarta. Hal. 26 - 28.

Tomas, C.R. 1997. Identifying Marine Phytoplankton. Academic Press Harcourt \& Company, San Diego-New York-Boston-London-Sydney-Tokyo-Toronto. $858 \mathrm{p}$

Yamaji, C.S. 1979. Illustration of the Marine Plankton of Japan. Hoikiska Publ. Co. Ltd., Japan. $572 \mathrm{p}$.

Yuliana. 2014. Keterkaitan antara Kelimpahan Zooplankton dengan Fitoplankton dan Parameter Fisika-Kimiadi Perairan Jailolo, Halmahera Barat. Maspari Journal. Vol. 6 (1) : 25 - 31. 